\title{
NOTAS
}

\section{El Criterio Generacional en la Literatura Paraguaya}

Carlos R. Centurión, el primero que hace un estudio orgánico de la literatura paraguaya, 1 la divide de acuerdo con la siguiente clasificación:

I) Epoca precursora, desde el descubrimiento hasta la independencia (I8II);

2) Epoca de formación, desde la independencia hasta el fin de la guerra de la Triple Alianza (1870);

3) Epoca de transformación, desde la Convención Nacional Constituyente (r870) hasta I9r3;

4) Epoca autonómica, desde $\mathrm{IgI}_{3}$ hasta nuestros días.

Si bien cabe destacar el enorme valor informativo de la obra de Centurión-fundamental, imprescindible para el estudio de las letras paraguayas-, la debilidad de la clasificación propuesta por el autor no puede escapar a una mínima observación detenida. La misma no obedece a ningún criterio determinado, y la vaguedad de los nombres de los períodos demuestra su arbitrariedad. Ellos no revelan nada del contenido cultural de las etapas y la clasificación se limita a dar cuenta de un pretendido cambio operado en la literatura, más o menos en función del proceso político del país. Centurión toma como base para su división

1 Carlos R. Centurión, Historia de la Cultura Paraguaya (2 tomos). (Asunción: Biblioteca "Ortiz Guerrero", 1961). 
- salvo para el punto de partida de la penúltima fase-el criterio de los períodos de la historia nacional, supeditando así el acontecer cultural al hecho histórico. Además, el último ciclo llega hasta el límite impreciso de "nuestros días".

En el presente ensayo nos proponemos hacer una clasificación de la literatura paraguaya teniendo en cuenta los estudios que han realizado los autores alemanes modernos ${ }^{2}$ sobre la generación - 30 años de promedio- como base de la periodología literaria, su aplicación a la literatura iberoamericana en general, y a las particulares de los distintos países del continente. En esta clasificación se evita el error arriba señalado, sin dejar de reconocer las relaciones estrechas existentes entre la literatura. y la realidad histórico-social. Pero nos preocupa sobre todo el contenido: de los períodos, el conjunto de obras y autores cronológicamente y estéticamente cercanos, que forman la base de la clasificación generacional de la literatura. Por eso las fechas y los nombres de las etapas se refieren: al acaecer cultural determinante o a los componentes estéticos predominantes. $Y^{\prime}$ la única vez que usamos el acontecimiento histórico como hito de una división-1935-, lo hacemos conscientes del cambio espiritual que el mismo trajo aparejado, y sólo como manifestación sensible de la experiencia generacional, destacando inmediatamente en la denominación' del periodo, la característica estética.

Al mismo tiempo, hemos de prescindir, en lo posible, de los nombres de los integrantes, cuya abundancia enumerativa no haría sino acarrearconfusión.

He aquí la clasificación de acuerdo con las bases propuestas:

I) La prehistoria literaria. Desde los origenes hasta 1878 .

2) La generación del Colegio Nacional y del Instituto Paraguayo (1878.19x3).

3) El Modernismo y la Defensa del Chaco (I9I3-I935).

4) Vanguardismo moderado y universalista (I935. ).

2 Filosofía de la Ciencia Literaria (México: Fondo de Cultura Económica, 1946). De entre los estudios contenidos en este libro utilizamos especialmente el de Julius Petersen: "Las generaciones literarias"; también el de H. Cysarz: "EI principio de los períodos en la ciencia literaria". Junto a éstos, los trabajos de Julián Marias, El método bistórico de las generaciones (Madrid: Revista de Occidente, 1949); y en forma principal el brillante ensayo de José Antonio Portuondo: "Periodos' y 'Generaciones' en la historiografía literaria hispanoamericana", en Cuadernos Americanos (México: Mayo-Junio de 1948, Vol. XXXIX, No. 3). Asimismo los estudios que aplican el criterio generacional a las distin. tas literaturas iberoamericanas. 


\section{Primer Período: La Prehistoria literaria - Desde los Inicios Hasta 1878}

Al estudiar la clasificación de la literatura hispanoamericana, los autores están contestes en aceptar la imposibilidad de hallar la división generacional durante los tres siglos de la Colonia, porque los factores históricos no permitieron la formación de las generaciones. Tales factores eran, por ejemplo, la presión de la metrópoli, que impedía la integración de grupos humanos fuera de los impuestos por ella misma; la condición - de culturas en formación, etc. Esta circunstancia hizo que esa etapa colonial no pueda sino ser dividida de siglo en siglo (Crónica, Barroco, Neoclasicismo), ${ }^{3}$ aunque a partir de la Independencia, en algunas literaturas, y desde comienzos del siglo xix en otras, se produce la sucesión generacional a través del libre juego de las tendencias y escuelas.

Con el Paraguay acontece algo particular, puesto que no solamente es imposible hacer una clasificación de siglo en siglo durante la Colonia, sino que aun después de producida la Independencia pasan largos años antes de que sea dable encontrar elementos que hagan factible considerar la existencia de un segundo período. No se niega con esto la producción literaria. La Colonia fue pródiga en crónicas -antecedente quizá de la predilección de los intelectuales paraguayos por la historia-, desde la de más alto valor literario escrita por el mestizo Ruy Díaz de Guzmán y la rimada de Centenera, hasta la obra de los jesuitas y los memoriales de los últimos días de la dominación española, pasando por los romances anónimos y las letrillas de fresco gracejo popular. Tampoco desconocemos los afanes - una verdadera cruzada, como muy bien demuestra Efraim Cardozo ${ }^{4}$ - por fundar una universidad y mejorar la instrucción, afán principalísimo, a su vez, de los primeros gobiernos independientes. Lo que queremos significar es que la producción existente -0 las noticias que de ella se tienen- no nos permite descubrir la existencia de tendencias estéticas definidas o movimientos literarios diferenciados. Lo mismo ocurre con la época independiente, hasta 1878 , debido especialmente a la nefasta impronta del dictador José Gaspar de Francia sobre la cultura,

3 José A. Portuondo lo hace así en el ensayo citado en la nota 2, siguiendo las bases de Pedro Henríquez Ureña en Las corrientes literarias en la América bis. pánica (México Fondo de Cultura Económica, 1949). Este autor es el primero que aplica el criterio generacional a la literatura iberoamericana.: El más reciente libro de conjunto es el de José Juan Arrom, Esquema generacional de las letras bispanoamericanas Ensayo de un método (Bogotá, 1963).

4 Efraím Cardozo, Historiografía paraguaya (México: Instituto Panamericano de Geografía e Historia, 1959); y "La cultura durante la colonia" (inédito). 
su labor negativa en este aspecto. Durante 26 años $\left(I 8 I_{4}-1840\right.$ ) de total encerramiento del país, se clausuraron casi todas las escuelas y todos los centros de cultura o de enseñanza superior a la primaria, o los de simple reunión; se prohibió la entrada de libros y periódicos. Los hombres de mediana instrucción y aun los alfabetos fueron encarcelados o puestos bajo vigilancia, por el peligro que implicaban para el dictador. Así, el Dr. Francia no sólo aplastó la generación que surgía con la Independencia, sino la que se hubiera desarrollado durante el tiempo de la dictadura (26 años es casi el lapso medio de toda una generación). Y su sombra se proyectó sobre las posteriores, que tuvieron que comenzar a construir sobre la nada.

Inicialmente habiamos llamado a este período: la prehistoria literaria y los inicios pre-románticos. Hemos suprimido la última parte de la denominación, aunque aquí debe constar que con la obra civilizadora, luminosa, del Presidente Carlos Antonio López (I842-1862) estaban comenzando a apuntar los primeros frutos en camino de sazón cuando advino la catastrófica guerra contra la Triple Alianza (1865-1870). A esta tarea nos referíamos al aludir a los inicios prerrománticos, nacidos en las lecciones del Colegio Carolino, de las labores del "Aula de Filosofia" y la "Academia Literaria" y de las páginas de La Aurora y El paraguayo independiente. Natalicio Talavera (I839-1867) es un testimonio de esta hermosa labor. $Y$ si no llegamos a considerar esta etapa como diferenciada del resto, es porque al ser aún débil el latido, pertenece a la categoría del pre.

$Y^{\prime}$ aquí entramos en la consideración del nombre del período: Prebistoria literaria. La prehistoria corresponde a la época en que se carece del documento. Nada más adecuado como concepto para aplicar a esta etapa en la cual, si existe el documento (la creación literaria), el mismo no posee la consistencia suficiente para concretar una corriente ideológica, una tendencia estética; debiendo destacarse, además, que si muchas veces se da la obra, ella está tan poco estudiada, que la valoración de la misma queda en la nebulosa del supuesto.

La denominación es asimismo comprensiva de la posible existencia de una literatura prehispánica, cosa difícil de comprobar por la ausencia del signo transmisor, aunque factible de ser intuida - una literatura oraldada la gran plasticidad de la lengua indígena, el guaraní-siempre vigente en el país-, y la natural habilidad que para la narración posee el campesino en torno al primario elemento mítico del fuego, y aún más 
con las recientes recopilaciones de textos religiosos y los estudios de León Cadogan ${ }^{5}$ y E. Schaden. ${ }^{6}$

Segundo Período: La Generación del Colegio Nacional Y DEL Instituto Paraguayo (I878-igi3)

En 1878, bajo la advocación de Benjamín Aceval (I845-1900), comienza a funcionar la institución que reunió a los integrantes de la primera generación literaria del Paraguay, primeramente como alumnos y luego como profesores, llegando varios de ellos a ejercer la dirección del Colegio Nacional de Asunción. Esta generación cobra mayor consistencia con las tareas cumplidas en el Instituto Paraguayo, centro de cultura superior, y tiene como medio de expresión principal a la revista del mismo.

La gente de la Convención Nacional Constituyente, con sus ideas liberal-individualistas, contribuye a formar la orientación ideológica de la generación, que se resuelve por la aceptación plena del positivismo. Sin embargo, de los forjadores de la Constitución todavía no se puede hablar como integrando una generación literaria o parte de ella, porque, fueron eminentemente escritores políticos, dedicados a la "literatura aplicada".

Aunque el espacio de treinta y cinco años que fijamos como lapso de vigencia de esta generación excede en cinco al promedio, dicho transcurso no es estricto y reconoce la elasticidad propia de los hechos culturales, más aún teniendo en cuenta que aquí se trata de un periodo inicial, es decir, el primero que va a constituir una generación en nuestras letras.

Caracterizaremos a este grupo a la luz del criterio empleado. De entre los elementos propuestos por los tratadistas, se cumplen casi todos, a saber: I) la coetaneidad resultante de la fecha de nacimiento; 2) los elementos educativos comunes, pues todos los integrantes se formaron en el Colegio Nacional, en donde adquirieron conciencia generacional (todos, con excepción de Alejandro Guanes (1872-1925), que también pertenece al grupo). Además, la formación libresca es también la misma, como se puede ver en la cita que hace Raúl Amatal de las "orientaciones memorables". ${ }^{7}$ 3) La comunidad personal es indudable, a través de la amistad,

5 León Cadogan. Ayvu rapyta (São Paulo: Boletím 227-Antropología, No. 5; Universidade de São Paulo, Faculdade de Filosofia, Ciencias e Letras, 1959); y Textos gutayakies sobre el Génesis (la misma edición, 1961).

6 E. Schaden. Aspectos fundamentais da cultura guarani. (São Paulo: Universidade de São Paulo, Faculdade de Filosofia, Ciencias e Letras, 1962).

7 Raúl Amaral. "Modernidad cultural del Paraguay", en Alcor (Asunción: Julio-agosto, No. 13, 1961). 
de la tertulia, de las redacciones, de la polémica, de la correspondencia. La historia literaria y sobre todo la pequeña historia, dan pruebas abundantes de ello. 4) La experiencia generacional inmediata es, indudablemente, la circunstancia cultural del Colegio Nacional, que los nuclea en el doble carácter aludido y la del Instituto Paraguayo, que - ambos-sirvieron de factores conglutinantes, aunque en el fondo estuvo muy presente el elemento catastrófico de la guerra, no ya demasiado reciente en el tiempo, pero aún muy candente en el espíritu de estos hombres, hasta el punto de constituir la experiencia real. 5) Fue ésta la que motivó el quehacer generacional, esto es, la elección del problema de la generación, que fue la necesidad imperativa de la afirmación de la nacionalidad, la recreación de la conciencia colectiva ante el peligro reciente de desintegración representado por la guerra. 6) En consecuencia postularon un nacionalismo que se resolvió estéticamente en fórmulas románticas, dando origen así al guía como prototipo ideal: el béroe. Muy bien dice Amaral que Juan E. O'Leary (I879) y Manuel Domínguez (r869-1935) hacen suyo el "culto de los héroes... en una necesaria contraposición dialéctica ...", ${ }^{8}$ refiriéndose al antagonismo con otro integrante de la generación, Cecilio Báez (r862-194I). Con referencia a este antagonismo, debemos recordar que el mismo fue con respecto a figuras como la de Solano López, presidente durante la guerra, pero Báez tuvo también el culto de los héroes pues era partidario del Dr. Francia, justificaba al dictador como el afianzador de la nacionalidad, aunque no aceptaba los posteriotes regímenes fuertes de los López. Cabe hablar de guía no como conductor, que no existió en ésta ni en otra generación. El séptimo. elemento, el lenguaje de la generación, resulta evidente de lo expuesto: romanticismo ampuloso y brillante, que aparecía como el más adecuado para la expresión del sentimiento patriótico, exaltado mas no agresivo. Lenguaje romántico predominante, aun considerado el racionalistmo positivista ideológico imperante, o teniendo en cuenta las premoniciones modernistas de Manuel Gondra (I87I-I927) y otros. En cuanto al último elemento, anquilosamiento de la anterior generación, nada podemos decir puesto que no existió; ellos no tenían contra quien luchar, en: este plano. Podemos decir, en síntesis, que es una generación base, y como generación, la mejor definida. Ella creó - al decir de Justo Pastor Benítez (h) ${ }^{9}$ - cierta característica que, en la línea del pensamiento, siguió teniendo vigencia por mucho tiempo, quizá hasta hoy, y que:

\footnotetext{
8 Ibid.

9 Justo P. Benítez (h.). Conversaciones con el autor.
} 
consiste en el imperio del positivismo, cuya influencia es consciente en Cecilio Báez y algún otro de su grupo, e inconsciente en los demás, y en los escritores de las siguientes generaciones. Dice Francisco Romero ${ }^{10}$ que una consecuencia del positivismo es el incremento de la historia y el derecho. La preocupación exagerada de los intelectuales paraguayos por la historia -entonces y después-es un rastro de la impronta positivista.

Tercer Período: El Modernismo y la

Defensa. del Chaco (1913-1935)

A fines de la primera década del presente siglo, se notan los síntomas de una renovación que se concreta en la fundación de la revista Crónica, cuyos creadores integran la primera promoción premodernista.

Los de esta generación no renuevan la base filosófica, que siguió siendo la orientación positivista; esto es, no ahondan en el porqué, limitándose al análisis de los hechos. Pero ésta se diferencia de la anterior (que como generación base es más acumulativa) en que es más creadora. Nacen en este lapso el teatro y la narrativa, y en contraposición al carácter de comentario, más bien, que informa la producción de la anterior generación, la nueva hace un intento de comprensión de los hechos históricos mediante el ensayo, género que ya corresponde a una etapa prefilosófica. Por otro lado, la base ideológica liberal-individualista es reemplazada, poco a poco, por un pensamiento social que, de actitud de protesta literaria, en la segunda y tercera décadas del siglo toma formas de lucha ideológica. El nacionalismo, que en la generación anterior tuvo condiciones de afirmación espiritual y manifestación estética, cobra en esta etapa modalidades agresivas y tinte político. Así se nota el surgimiento de una teoría indigenista extrema - por ejemplo- que pretende interpretar nuestra cultura en base a valores preponderantes autóctonos.

Esia generación estuvo integrada por dos promociones surgidas, la primera con la revista Crónica, la segunda con Juventud (I913 y I923, respectivamente), y ambas pertenecientes a la escuela modernista, que llega con retraso, pues las primeras manifestaciones de esta tendencia -las del grupo Crónica - son de origen y expresión más bien parnasianosimbolistas, y no configuran aún los signos de la escuela modernista, por falta de tónica y rápida consunción. La expresión propiamente moder.

10 Francisco Romero, Teoria del bombre (Buenos Aires: Losada, 1957). 
nista - $y$ exageradamente rubendariana- se manifiesta recién con Jwventud, en I923, cuando ya la escuela había desaparecido y en el resto de América la vanguardia disparaba sus ráfagas de rebeldía antiacadémica. Todo esto en lo que a caracteres generales se refiere. Al ubicar los elementos que configuran la definición generacional, veremos las particularidades.

Referente a la coetaneidad resultante de las fechas de nacimiento, la promoción de Crónica está integrada por escritores nacidos entre I889 y I898, y la de Juventud, entre I900 y r9o8. Aquéllos adquirieron los elementos educativos primarios en el Colegio Nacional, donde se formaron todos; y los segundos en el de San José, donde estudiaron casi todos. Herrera y Reissig y Darío fueton los modelos, en tanto que Rodó el ideólogo más admirado. En ambos casos la experiencia generacional fue cultural, la fundación de una revista literaria. En cuanto a la tarea que se impusieron, fue, según declaración en carta de Pablo Max Ynsfrán (I894) a Raúl Amaral, "poner al día la literatura paraguaya", para lo cual adhirieron al Modernismo, anticipado por Eloy Fariña Núñez (I885I929), que por haberse formado y actuado en Buenos Aires, escapa a la ubicación dentro del grupo.

La "literatura aplicada" siguió siendo scaparada - de acuerdo con el carril positivista- por la historia, a la que se suma en esta etapa el ensayo, que adquiere--como ya dijimos-, en algunos, virulencia nativista o furia nacionalista. En la segunda y tercera décadas este afán se orienta en un sentido principal: la defensa de los derechos del Paraguay sobre el Chaco en disputa. Esto se convierte en verdadera tarea o quehacer que explica la segunda parte de la denominación del periodo. Mediante estas labores, impuestas por la necesidad, nace la investigación histórica seria, que culmina en la siguiente etapa con la formación de un grupo responsable de historiadores. El lenguaje de la generación es el modernista, claramente revelado, aun en la obra de los ensayistas e historiadores. En cuanto al guía, no existió; y si cabe señalar algún prototipo, éste es el bohemio, pero esencialmente como comportamiento, como ideal de vida, bajo la influencia de la bohemia parisina de Darío y su grupo, y con la inspiración remota de un resto romántico. Este ideal es más evidente en los componentes de la promoción de Crónica. Finalmente, en lo que se refiere al anquilosamiento de la anterior generación, ello no se produjo en forma inmediata, ni tampoco se hizo la negación de la antigua por la nueva. Al contrario, los restos de aquélla convivieron con ésta, a la que legaron su orientación positivista, entre otras cosas. Pero es natural que 
ocurra así dada la circunstancia del ambiente cultural pequeño en el cual existen poderosos vínculos de amistad o parentesco. Además, no hay que olvidar que la renovación estuvo latente en algunas manifestaciones de la generación anterior, y que la escuela modernista advino -como que llegó tardíamente- sin el impulso avasallador del signo inicial. Como vemos, están dados los elementos fundamentales para constituir una generación.

\section{Cuarto Período: Vanguardismo Moderado \\ Y UINIVERSALISTA $($ I935 ...)}

El Modernismo siguió manifestándose todavía un tiempo. No obstante, al finalizar la guerra del Chaco (I935) hay síntomas de cambios anticipados por el sacudón de la contienda y los acontecimientos políticosociales inmediatamente posteriores a la misma. Esta inquietud aventa en los poemas sociales, toscos de Julio Correa (I890-I953), precursor inconsciente, y en el libro El precio de los sueños y la labor de Josefina $\mathrm{Pla}$, iniciadora consciente de las renovaciones. Uno de los benjamines de la promoción de Juventud, Herib Campos Cervera (I908-1953), influyó poderosamente para el cambio y la adquisición de la conciencia generacional. Estos y otros nombres integran una primera promoción cuyos componentes no forman un grupo estrechamente cohesionado. Otra promoción surge en torno a I950 (la que se nuclea en la Facultad de Filosofía y la Academia Universitaria), y una tercera apunta diez años más tarde.

Indudablemente es un poco prematuro hablar todavía de esta generación, por la falta de perspectiva, ya que está en plena elaboración, cumpliendo el desarrollo de sus objetivos. Pero es indudable que ya posee elementos que han de configurar una generación.

Salvando la presencia de los precursores e iniciadores, que son contemporáneos, mas no coetáneos, se puede hablar de las fechas de nacimiento cercanas, de los elementos educativos revelados en lecturas comunes y orientadoras de los autores más modernos (tomada esta palabra en el sentido de lo que es moderno, en I 960 y tantos, para el lector cultivado e inquieto de cualquier parte), y en la formación de una conciencia de responsabilidad, en cuya concresión juega un papel la Facultad de Filo. sofía, fundada en I948. La comunidad personal de las distintas promociones está dada por el cenáculo "Vy'a raity", la Facultad de Filosofía, la Academia Universitaria y las revistas y ediciones Alcor, Diálogo y Asedio, 
además del trato particular entre los integrantes. La experiencia generacional es, por un lado, la situación política adversa a una libre manifestación, que da origen a una literatura social, y por otro la Facultad de Filosofía, la Academia Universitaria y las revistas citadas, empresas fundadas por la época, y que prestan unidad a la labor cultural. Esta tarea es la incorporación de nuestra literatura en el concierto de la del mundo y en su hora presente, así como la fundamentación responsable de la "literatura aplicada", y la creación de un pensamiento filosófico diferente. No hay duda que el lenguaje de esta generación es el de la vanguardia moderada, heredera de los "ismos" iconoclastas, que nunca existieron en el Paraguay, por la tardanza con que se incorpora la experiencia. También es indiscutible la caducidad del Modernismo ante los embates de la última generación, que sin embargo tampoco fue irreverente o destructora. El guía no existe, aunque no se puede negar la influencia de Campos Cervera como ejemplo y el maestrazgo de Josefina PIa.

Con estos elementos volvamos al nombre del período: vanguardismo moderado y universitalista. Vanguardismo porque el mismo participa de las características generales del-movimiento que, genéricamente, se conoce con esta denominación, sucesor de los "ismos" renovadores de la segunda década del siglo. Es moderado porque llega en momentos en que ya no tiene la violencia destructora inicial, lo cual no quiere decir que sea pasatista - por primera vez en la historia de nuestra literatura-ya que está en la hora de su tiempo universal. De ahí una de las razones del universalismo que se caracteriza en el nombre. La otra es su determinación de incorporar los valores de la cultura universal, sin que esto implique una renuncia a los elementos propios.

El resultado que ya se puede apuntar es el auge de un movimiento poético vigoroso; el cultivo de una narrativa moderna; el afianzamiento de un ensayo responsable y de una historia científica (nacida en el período anterior), y la conciencia de la necesidad - al borde de la creación-de un pensamiento filosófico distinto, que ha de reemplazar la rutina positivista. En síntesis un criterio más cabal de la responsabilidad del intelectual y del artista.

Estas notas echan la base de una clasificación de la literatura paraguaya usando, por primera vez en forma orgánica, el criterio generacional. Clasificación que es provisoria en el sentido de una posible rectificación o ajuste, mediante el estudio de los elementos que integran cada una de las divisiones, y sobre todo de la última. Con respecto a este período final, debemos aclarar que no hemos fijado fecha límite porque aún no existen 
síntomas más o menos precisos que nos permitan hacerlo. Lo cual no significa que por comodidad lo hayamos extendido irresponsablemente "hasta nuestros días". Consideramos que las últimas promociones no se diferencian sustancialmente de las anteriores, razón por la cual, la incluimos-provisoriamente- dentro de la última división.

No es un criterio caprichoso el que nos movió a realizar este trabajo, sino el deseo de trazar una trayectoria de nuestra literatura como el esfuerzo de las generaciones por ir buscando "la propia expresión"; criterio científicamente aceptado como el mejor para el estudio de la literatura, ya que la generación es un concpto de bases biológicas y cumplimiento necesario - no así estricto o simétrico-que trae el natural cambio de visión del mundo, de acuerdo con las notas características diferenciales de cada época.

Con esta clasificación no se pretende hacer compartimientos estancos ni consagrar nombres, sino que se trata de prestar una ayuda al estudio de nuestra historiografía literaria, al caracterizar el surgimiento de una determinada tendencia y buscar sus más profundas razones culturales y sociohistóricas.

RubéN Bareiro SAGUIER

Asunción, Paraguay. 
